\title{
Surgical management of epilepsy
}

\author{
Nathalie Jette MD MSc, Aylin Y. Reid MD PhD, Samuel Wiebe MD MSc
}

See related commentary on page 973 and at www.cmaj.ca/lookup/doi/10.1503/cmaj.140427

$\mathrm{E}$ pilepsy is the second most commonly reported neurologic condition worldwide and affects people of both sexes and of all ages and socioeconomic statuses. ${ }^{1}$ It is a frequent reason for consultation in primary care, and $80 \%$ of epilepsy costs are attributed to patients with drug-resistant epilepsy. ${ }^{2}$ Patients for whom medical treatment fails may be candidates for surgical intervention.

The modern era of epilepsy surgery began in England in the late 1800s, with a focus on neocortical resection. ${ }^{3}$ In the 1940s, Jasper and Penfield began performing mesial temporal lobe resections at the Montreal Neurological Institute; this is now the most commonly performed surgery for treatment of epilepsy. ${ }^{3}$ However, epilepsy surgery remains underutilized. For example, a recent report from the Ontario Health Technology Advisory Committee estimated that $2 \%$ of Ontario patients eligible for such surgery actually received it. ${ }^{4} \mathrm{We}$ review the indications for and the benefits and risks of surgical interventions for epilepsy based on evidence from randomized controlled trials, cohort studies and case series (Box 1).

\section{What are the limitations of medical therapy for epilepsy?}

The natural history of epilepsy in those taking antiepileptic drugs has been explored in several long-term, population-based cohort studies..$^{5-8}$ The probability of achieving one-year freedom from seizures after trying two to three drugs is between $63 \%$ and $79 \%$ (95\% CI 53\%-81\%). ${ }^{5-7}$ However, as many as $68 \%$ (95\% CI $65 \%-70 \%)$ of patients with focal epilepsy are resistant to drug therapy, ${ }^{9}$ which means that adequate trials of medical therapy with two "tolerated, appropriately chosen and used antiepileptic drug schedules have failed to achieve sustained seizure freedom"10 ("adequate" implies appropriate drug treatment of sufficient strength whether as monotherapy or in combination). Failure of two or more antiepileptic drugs to sustain freedom from seizures is associated with a poor prognosis. Patients are unlikely to respond to additional drug treatment. ${ }^{5,10,11}$ Only $3 \%-5 \%$ of such patients per year eventually achieve seizure remission periods of one year with further antiepileptic drug therapy, and seizures recur in $71 \%-80 \%$ of these patients. ${ }^{11,12} \mathrm{~A}$ recent review of the impact of epilepsy showed that uncontrolled epilepsy is not only costly but is also associated with adverse cognitive effects, poor quality of life and increased mortality. ${ }^{13}$

\section{Which surgical procedures are available to treat epilepsy?}

Whether seizures are focal or generalized determines the type of surgical procedure. Complete resection of the epileptogenic focus leads to the best results - that is, freedom from seizures. ${ }^{14,15}$ For patients in whom resection of the epileptogenic zone is impossible because it overlaps with eloquent cortex that would result in neurologic deficits, nonresective procedures may be indicated. These less commonly performed procedures include corpus callosotomy and vagus nerve stimulation. These are generally less effective than complete removal of the epileptogenic zone. Surgical interventions for patients with epilepsy can be grouped into three main categories.

\section{Surgical resection or disconnection}

For patients who experience seizures with focal or regional onset, surgical resection is the optimal procedure. This is the most common surgical inter-

\section{- Ker poInTS}

- Patients who continue to have seizures despite appropriate trials of two antiepileptic drugs are unlikely to ever achieve sustained freedom from seizures with medical therapy.

- Surgical resection of the epileptogenic focus in carefully selected patients is highly effective, has durable effects and is cost-effective.

- Major complications of epilepsy surgery are infrequent and usually temporary but may rarely include dysphasia, memory decline and hemiparesis.

- Epilepsy surgery should be considered for patients with drug-resistant epilepsy and disabling seizures.

- Although best results are seen for focal epilepsy, surgery can also be considered for patients without a clear lesion on neuroimaging and those with generalized epilepsy. 
vention. Most of the evidence discussed below pertains to resective surgery, in which patients undergo a craniotomy and resection of the brain tissue containing the epileptogenic focus. Patients are eligible for this procedure if the epileptic zone is fairly circumscribed and limited to a noneloquent area that can be safely removed. The presence of a lesion on a magnetic resonance image (MRI; e.g., hippocampal sclerosis) increases the likelihood of surgical candidacy and of achieving freedom from seizures. In patients without a lesion detected by MRI, the seizure focus to be resected is determined by use of additional modalities to map the seizure origin by scalp or intracranial ictal electroencephalography (EEG) recordings and through functional imaging (e.g., single-photon emission computed tomography [SPECT] or positron emission tomography [PET]).

Disconnection procedures are palliative surgical procedures that can be performed in patients who do not have a resectable seizure focus. Patients with seizures of broadly synchronous, bi-hemispheric origin can undergo partial or complete section of the corpus callosum with the aim being to reduce drop attacks (i.e., atonic seizures) that are associated with sudden loss of tone and falls. The mechanism by which this procedure works is not clear, but it likely relates to a decrease in the magnitude of synchronous discharges involving both hemispheres.

\section{Ablative procedures \\ Minimally invasive surgical procedures such as radiofrequency ablation using stereotactically implanted probes have been assessed more recently, in particular for mesial temporal lobe epilepsy, but the results have been variable. ${ }^{16}$ The main advantages are less invasive surgery (usually through a burr hole), precise targeting of the seizure-producing foci, and minimum disruption of}

\section{Box 1: Evidence for this review}

A systematic review of studies indexed in MEDLINE, Embase and the Cochrane Database had previously been completed by members of our team as part of an appropriateness study of epilepsy surgery (see www.epilepsycases.com) to identify all epilepsy surgery-related articles published before 2008. The search strategy included text words and subject headings of variations of the terms: epilepsy and surgery AND incidence, predictors, prognosis, course, outcome, mortality, SUDEP (sudden unexplained death in epilepsy), survival, psychology, quality of life, memory, seizure, utilization, cost, efficacy, effectiveness, complications AND randomized controlled trial or double blind or placebo controlled or drug therapy or therapeutic or cohort study or case control or clinical trial or random allocation or case series or decision analysis or economic or risk or odds ratio or relative risk. All studies included in this review were hand-searched for citations of relevance. To identify studies published after January 2008, we searched MEDLINE and the Cochrane Database (up to June 26,2012 ), applying search parameters described above to identify pertinent English-language articles. Abstracts $(n=2269)$ were reviewed by one study author (N.J.) to identify relevant full-text articles. healthy brain tissue. Ablation of epileptogenic brain tissue using highly focused radiation (radiosurgery) requiring no craniotomy is an experimental procedure currently being tested in randomized controlled trials (RCTs), ${ }^{17}$ and it is used most frequently for well-delineated lesions causing epilepsy. The main disadvantages are delayed benefit (usually starting $12 \mathrm{mo}$ after the procedure) and the risk of clinically substantial brain edema (50\%$60 \%$ ) requiring treatment with corticosteroids and, less frequently, decompressive craniotomy. ${ }^{17}$

\section{Therapeutic devices}

Randomized controlled trials of electrical stimulation of peripheral nerves, in particular vagus nerve stimulation, and stimulation of brain cortex or deep brain nuclei for the treatment of epilepsy have been undertaken. ${ }^{18-21}$ Stimulation procedures show a modest benefit in seizure frequency and are often reserved for patients who cannot undergo resective epilepsy surgery.

\section{What investigations should precede epilepsy surgery?}

For all types of epilepsy surgery, careful clinical evaluation is required to determine the extent and location of the seizure focus and the function of the involved area of the brain. This usually requires detailed assessment by epilepsy specialists, MRI of the brain using protocols that are more sensitive to detect relevant abnormalities, video EEG monitoring to record typical seizures, and neuropsychological assessment of baseline cognitive function. In recent years, novel functional imaging (e.g., functional MRI, PET, SPECT, functional connectivity) and neurophysiological diagnostic modalities (e.g., detection of high-frequency oscillations or assessment of neuronal connectivity using intracranial EEG recording, magnetoencephalography) have greatly enhanced presurgical planning by increasing the likelihood of identifying lesions not seen on MRI of the patient's brain. ${ }^{22}$ However, the effectiveness of these novel diagnostic tools for surgical decision-making has not been well studied and their accuracy for use in planning epilepsy surgery remains to be determined. ${ }^{23}$

\section{What are the benefits of epilepsy surgery?}

Cohort studies and RCTs (Table 1) consistently show that, in focal drug-resistant epilepsy, resective brain surgery results in seizure freedom for about $57 \%$ of patients who undergo neocortical resections and for $70 \%$ of those who undergo anteromesial 
temporal resections, compared with 5\%-8\% of patients receiving optimum medical therapy. ${ }^{14,15,52,26}$ The number of patients needed to be treated with surgery for one additional patient to become seizure free is two. ${ }^{14,15} \mathrm{In}$ a recent RCT comparing medical therapy to early surgery in patients with temporal lobe epilepsy, $73 \%$ of patients in the surgical group became seizure free during the second year of follow-up, compared with $0 \%$ in the medical group. ${ }^{15}$ A meta-analysis of one RCT and 19 observational studies comparing surgery with medical therapy found an absolute risk reduction of
$42 \%$ (95\% CI 32\%-51\%) for any seizure recurrence in patients who underwent surgery. ${ }^{27}$ Similar surgical outcomes have been reported in cohort studies involving older patients. ${ }^{28} \mathrm{~A}$ recent observational study involving children under three years of age found that $48 \%$ were seizure-free after surgery and that seizures decreased by more than $75 \%$ in an additional $38 \%$ of patients. ${ }^{29}$

Although resective surgeries have been shown to provide the most benefit, other procedures can also reduce the frequency of seizures. Corpus callosotomy has been shown in cohort studies to

Table 1: Summary of randomized controlled trials of temporal lobe epilepsy surgery

\begin{tabular}{|c|c|c|}
\hline No. of patients & $\begin{array}{c}\text { Wiebe et al. }{ }^{14} \\
\quad n=80\end{array}$ & $\begin{array}{c}\text { Engel et al. }{ }^{15} \\
\quad n=36\end{array}$ \\
\hline Study setting & - Single centre, tertiary care & - Multicentre, tertiary care \\
\hline Patient population & $\begin{array}{l}\text { - } \text { Drug-resistant temporal lobe epilepsy } \\
\text { - } \text { Average age (yr): medical group: } 34.4 \pm 9.9 \text {; } \\
\text { - Female: medical group: } 47.5 \% \text {; surgical group; } \\
57.5 \% \\
\text { - No. of antiepileptic drugs before } \\
\text { randomization, median: medical group: } 6 \text {; } \\
\text { surgical group: } 6\end{array}$ & $\begin{array}{l}\text { Drug resistant temporal lobe epilepsy for } \leq 2 \mathrm{yr} \\
\text { - } \text { Average age (yr): medical group: } 30.9 \pm 10.1 \text {; } \\
\text { surgical group: } 37.5 \pm 11.1 \\
\text { - Female: medical group: } 39.1 \% \text {; surgical group: } \\
73.3 \% \\
\text { - Mean number of antiepileptic drugs used: medical } \\
\text { group }=1.9 \text {; surgical group }=1.6\end{array}$ \\
\hline Interventions & $\begin{array}{l}\text { - Anteromesial temporal lobe resection, } n= \\
40 \\
\text { - Ongoing treatment with antiepileptic drugs, } \\
n=40\end{array}$ & $\begin{array}{l}\text { - Anteromesial temporal lobe resection, } n=15 \\
\text { - Ongoing treatment with anti-epileptic drugs, } n= \\
23\end{array}$ \\
\hline Duration of follow-up & $1 \mathrm{yr}$ & $2 \mathrm{yr}$ \\
\hline $\begin{array}{l}\text { Primary outcome and } \\
\text { results }\end{array}$ & $\begin{array}{l}\text { Freedom from seizures that impair awareness } \\
\text { of self and surroundings (cumulative } \\
\text { proportion of patients seizure-free at one } \\
\text { year, } p<0.001^{*} \text { ): surgical group: } 58 \%(64 \% \\
\text { excluding those who did not undergo } \\
\text { surgery); medical group: } 8 \%\end{array}$ & $\begin{array}{l}\text { - Freedom from disabling seizures: number of } \\
\text { seizure-free patients at } 2 \text { yr }(\mathrm{OR} \infty, 95 \% \mathrm{Cl} 11.8 \text { to } \\
\infty, p<0.001 \text {; surgical group: } 11 / 15 ; \text { medical group: } \\
0 / 23\end{array}$ \\
\hline $\begin{array}{l}\text { Secondary outcomes } \\
\text { and results }\end{array}$ & $\begin{array}{l}\text { - Frequency and severity of seizures (free of } \\
\text { all seizures, } p<0.001 \text { )*: surgical group: } 38 \% \\
\text { ( } 42 \% \text { excluding those who did not undergo } \\
\text { surgery); medical group: } 3 \% \\
\text { - } \quad \text { Percentage improvement in monthly } \\
\text { frequency of seizures impairing awareness, } \\
\text { median: surgical group: } 100 \% \text {; medical } \\
\text { group: } 34 \% \\
\text { Quality of life (QOLIE-89) at one year ( } p< \\
0.001) \dagger \text { : surgical group: } 73.8 \text {; medical group: } \\
64.3 \\
\text { Disability (percentage of patients employed } \\
\text { or attending school at one yr, } p=0.1 \text { ): } \\
\text { surgical group: } 56.4 \% ; \text { medical group: } 38.5 \% \\
\text { Death: surgical group: } 0 ; \text { medical group: } 1\end{array}$ & $\begin{array}{l}\text { - Quality of life (QOLIE-89), mean improvement } \\
\text { (intention-to-treat; } p=0.08) \text { : surgical group: } 12.6 \text {; } \\
\text { medical group: } 4.0 \\
\text { - Cognitive function (memory decline; Rey Auditory } \\
\text { Verbal Learning Test): surgical group: } 4 \text { patients } \\
\text { (36\%); but the study was underpowered to permit } \\
\text { definite conclusions about treatment group } \\
\text { differences } \\
\text { - } \text { Driving at } 24 \text { mo }(p<0.001) \text { : surgical group: } 80 \% \text {; } \\
\text { medical group: } 22 \% \\
\text { - Days per month of socializing with friends ( } p= \\
\text { 0.002), median: surgical group: } 6.5 \text { d; medical } \\
\text { group -1 d } \\
\text { Employment status, sick days or socialization with } \\
\text { family: no treatment group difference } \\
\text { Adverse events: transient neurologic deficit in } 1 \\
\text { patient in the surgical group and } 3 \text { cases of status } \\
\text { epilepticus in the medical group }\end{array}$ \\
\hline Number needed to treat & $\begin{array}{l}\text { - Freedom from seizures impairing awareness: } \\
2(95 \% \mathrm{Cl} 1.5-3) \\
\text { - } \quad \text { Freedom from all seizures: } 3(95 \% \mathrm{Cl} 2-5)\end{array}$ & - $2(95 \% \mathrm{Cl} 1.1-2.3)$ \\
\hline
\end{tabular}


decrease the number and severity of seizures: five years after surgery about $35 \%$ of patients were reported to be free of drop attacks. ${ }^{30}$ Randomized controlled trials have shown that vagal nerve stimulation can reduce seizures by $25 \%$ on average (95\% CI 14\%-34\%), ${ }^{18}$ and RCTs have also shown a net improvement (active minus control) in seizure frequency of $15 \%$ (interquartile range $2 \%-24 \%$ ) with hippocampal stimulation, ${ }^{19} 20 \%(p=0.01)$ with recursive cortical stimulation, ${ }^{20}$ and $26 \%(p=0.001)$ with stimulation of the anterior thalamus. ${ }^{21}$
Although comparative trials to date have not been designed to assess mortality, a cohort study of patients who received epilepsy surgery found that those who remained seizure-free had mortality rates similar to the general population, while those who had recurrent seizures had a standardized mortality ratio of 4.7. ${ }^{31}$ Decision analysis models have shown a five-year (95\% CI 2.1-9.2 yr) increase in life expectancy following surgery, as compared with medical therapy. ${ }^{32}$ Quality of life has been reported to be improved after epilepsy surgery in $90 \%$ of studies assessing this

Table 2: Frequency of medical complications: overall, by age group and location of resection

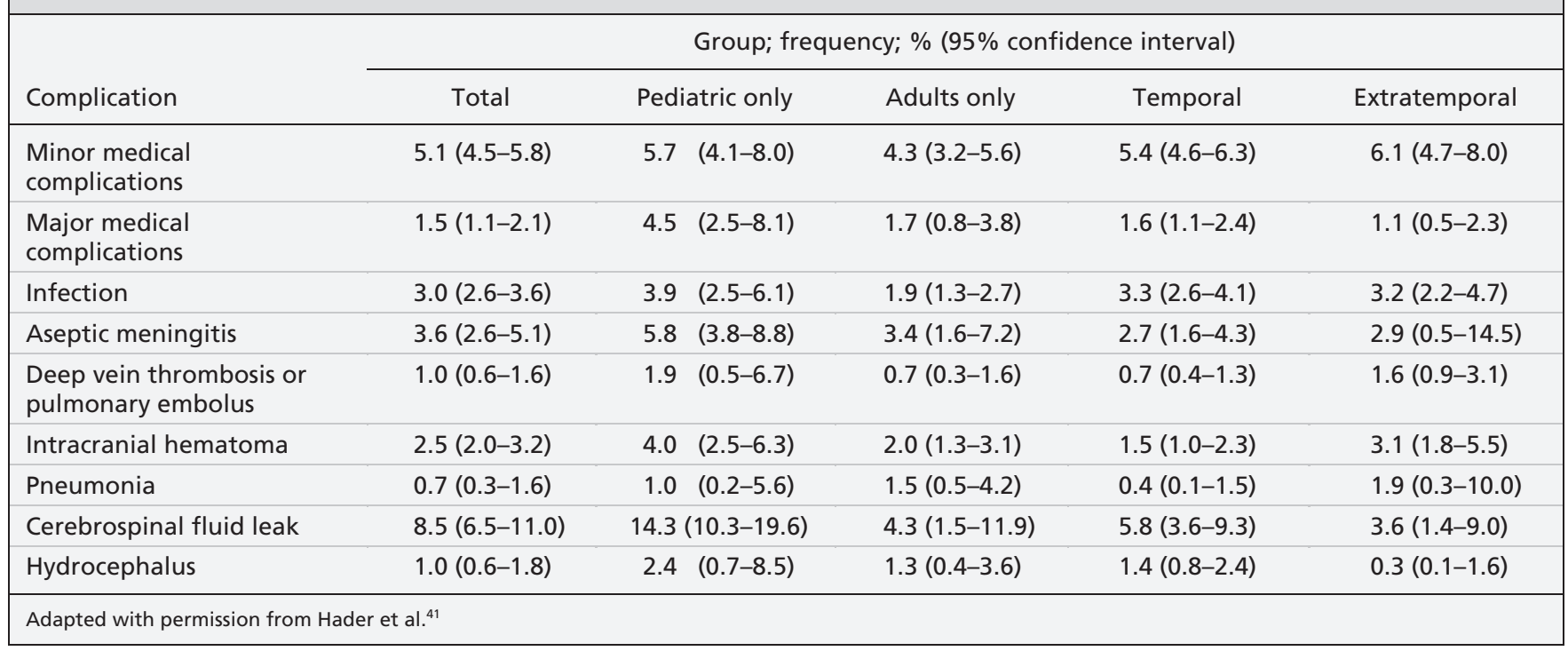

Table 3: Frequency of neurologic complications: overall, by age group and location of resection

\begin{tabular}{|c|c|c|c|c|c|}
\hline Complication & Total & Pediatric only & Adults only & Temporal & Extratemporal \\
\hline Minor neurologic complications & $10.9(10.1-11.7)$ & $11.2(9.5-13.2)$ & $5.5(4.4-6.8)$ & $11.5(10.5-12.5)$ & $11.9(9.9-14.2)$ \\
\hline Major neurologic complications & $4.7(4.1-5.3)$ & $5.1(3.9-6.7)$ & $3.3(2.4-4.5)$ & $4.1(3.5-4.8)$ & $6.5(5.2-8.2)$ \\
\hline Minor cranial nerve & $2.1(1.6-2.7)$ & $8.3(2.3-25.8)$ & $2.3(1.5-3.7)$ & $2.3(1.7-3.0)$ & $0.9(0.4-2.3)$ \\
\hline Minor field & $12.9(11.5-14.5)$ & $6.3(4.3-9.0)$ & $15.7(11.0-21.9)$ & $17.9(15.8-20.2)$ & $7.2(4.0-12.8)$ \\
\hline Major field & $2.1(1.7-2.7)$ & $3.9(2.2-6.7)$ & $1.4(0.8-2.5)$ & $2.3(1.7-3.0)$ & $2.8(1.9-4.3)$ \\
\hline Minor dysphasia & $3.7(3.1-4.3)$ & $2.1(1.2-3.7)$ & $2.1(1.4-3.1)$ & $14.0(3.3-4.8)$ & $3.7(2.6-5.1)$ \\
\hline Major dysphasia & $0.8(0.5-1.3)$ & $0.5(0.1-3.1)$ & $1.4(0.7-3.1)$ & $0.9(0.5-1.5)$ & $1.5(0.6-3.8)$ \\
\hline Minor memory & $5.1(3.9-6.5)$ & NA & $3.2(1.1-9.0)$ & $5.6(4.3-7.3)$ & $0(0-4.5)$ \\
\hline Minor psychiatric & $5.5(4.4-6.8)$ & NA & NA & $5.8(4.6-7.3)$ & $1.6(0.6-4.7)$ \\
\hline Major psychiatric & $1.9(1.1-3.4)$ & NA & NA & $1.9(1.1-3.4)$ & NA \\
\hline
\end{tabular}


outcome using various methods and instruments. ${ }^{33}$ Systematic reviews have also shown improvements after epilepsy surgery in employment, social function and overall lifestyle. ${ }^{34}$

Economic evaluations performed in Canada and France show that the cost-effectiveness ratio favours epilepsy surgery over medication after the eighth postsurgical year, when surgery becomes more cost-effective than medication because of its ability to avert seizures. ${ }^{35,36} \mathrm{~A}$ recent economic evaluation found that at a cost of \$25020 per quality-adjusted life year, epilepsy surgery was cost-effective compared with medical therapy. ${ }^{37}$

Surgery can achieve durable seizure control in patients with drug-resistant epilepsy. Sustained freedom from seizures persists for greater than five years in $66 \%$ (95\% CI 62\%-70\%) of patients with temporal lobe resections and in 59\% (95\% CI $59 \%-62 \%$ ) with temporal and extratemporal resections. ${ }^{30}$ Although a lesion found on MRI is a strong predictor of sustained seizure freedom with surgery, patients without MRI lesions may still achieve substantial rates of seizure freedom with surgery $(70 \%$ seizure freedom if a lesion is present v. $43 \%$ if no lesion). ${ }^{38}$ Meta-analyses of cohort studies and one RCT showed that about 50\% (95\% CI 45\%-55\%) of patients who undergo epilepsy surgery are able to decrease their multiple antiepileptic drugs to a single drug ${ }^{39}$ and about 22\% (95\% CI 20\%-25\%) are able to discontinue all antiepileptic drugs and may be considered "cured" of epilepsy. ${ }^{39}$ Shortterm gains achieved with surgery in psychosocial function (e.g., improvement in quality of life and psychological well-being) also persist in the long term (e.g., five or more years). ${ }^{39,40}$

\section{What adverse effects are associated with resective epilepsy surgery?}

A recent systematic review including 73 observational studies, two RCTs and a large population-based cohort study found that surgery had a low overall rate of complications $(5 \%-11 \%)$ and that most complications were reversible. ${ }^{41} \mathrm{~A}$ summary of possible minor and major medical and neurologic complications associated with focal resective surgery are presented in Table 2 and Table $3 .^{41}$ Perioperative mortality is uncommon $\left(0.6 \%\right.$ in the above systematic review $\left.{ }^{41}\right)$, and no deaths were reported in the surgical groups of the RCTs of temporal lobe epilepsy

Table 4: Predictors of adverse events associated with epilepsy surgery ${ }^{41}$

\begin{tabular}{|llc|}
\hline Adverse event & \multicolumn{1}{c|}{ Predictor } & Risk, $\%$ \\
\hline Intracranial hematoma & Extratemporal v. temporal resection & 3.1 v. 1.5 \\
\hline Hydrocephalus & Children v. adults & 2.4 v. 1.3 \\
\hline Minor visual field defect & Temporal v. extratemporal resection & 17.9 v. 7.2 \\
\hline Minor or temporary hemiparesis & Extra-temporal v. temporal resection & 7.9 v. 1.8 \\
\hline Verbal memory decline & Left-sided v. right-sided surgery & 44 v. 20 \\
\hline
\end{tabular}

Table 5: Which patients should be referred to a comprehensive epilepsy program for an epilepsy surgery evaluation?

Any child or adult who meets the definition of drug-resistant epilepsy and has disabling seizures

Children or adults with complex syndromes or requiring complex surgeries

Children or adults with epilepsies that cannot be clearly assigned to a known electroclinical syndrome but with stereotyped or lateralized seizures or focal findings

Children with an MRI lesion amenable to surgical removal regardless of seizure status
Drug-resistant epilepsy: Failure of adequate trials of 2 tolerated, appropriately chosen and used antiepileptic drugs (whether as monotherapies or in combination) to achieve sustained seizure freedom. ${ }^{10}$

Examples of complex syndromes: Rasmussen encephalitis, tuberous sclerosis, Sturge-Weber syndrome, Landau-Kleffner syndrome, polymicrogyria, hypothalamic hamartoma, Dravet syndrome, Lennox-Gastaut syndrome, West syndrome, Ohtahara syndrome, infantile spasms, epilepsia partialis continua. Examples of complex surgeries: hemispherectomies, multilobar resections, palliative procedures

The International League Against Epilepsy has proposed a new classification of seizures and epilepsies. ${ }^{45}$

Recommended by the Subcommission for Pediatric Epilepsy Surgery of the International League Against Epilepsy because these children are more likely to relapse, and are at high risk of developing epileptic encephalopathy, especially at a younger age. ${ }^{46}$

Modified with permission from Wiebe and Jette..$^{33}$ 
surgery (Table 1). ${ }^{14,15,41}$ Interestingly, the overall risk of major complication associated with epilepsy surgery is similar to that reported in large RCTs of carotid endarterectomy (6\%). ${ }^{41}$

It is difficult to identify statistically robust predictors of adverse events associated with epilepsy surgery because complications are infrequent. In Table 4, we provide examples of complications that are twice as likely or more to occur in certain populations or with particular types of resections, ${ }^{41}$ including some of the neuropsychological complications. Fortunately, the risk of memory decline is low in children $(5 \%) .{ }^{42}$ For a more detailed discussion about the neuropsychological outcomes after epilepsy surgery,

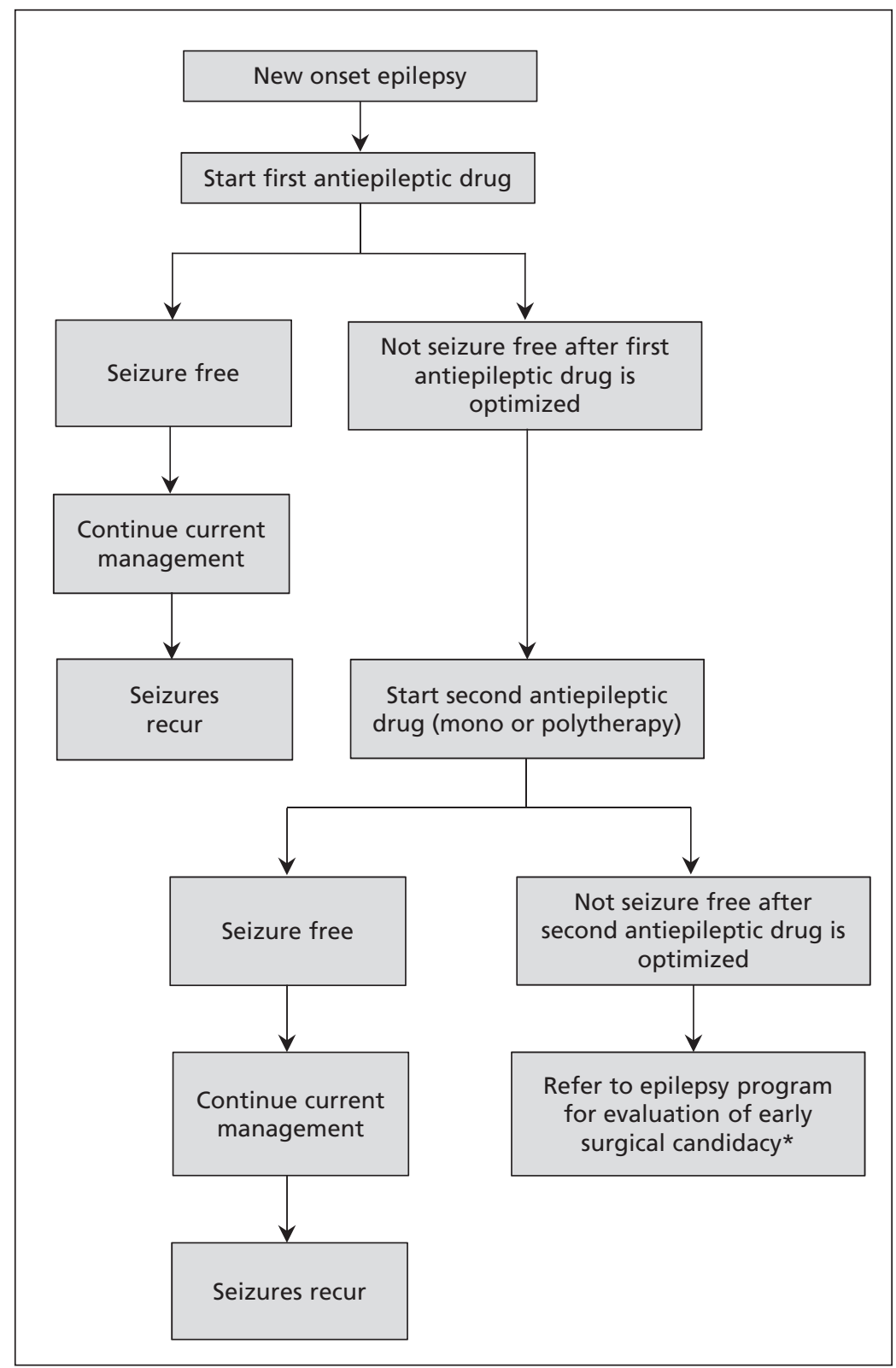

Figure 1: Approach to the care of a patient with newly diagnosed epilepsy. *This step should be reached within one year or as soon as two antiepileptic drugs have been attempted and failed. please see a recent systematic review by Sherman and colleagues. ${ }^{42}$ Importantly, cohort studies show that quality of life improves if patients become seizure-free following surgery, regardless of neuropsychological outcomes. ${ }^{43}$

\section{Who should be considered for epilepsy surgery?}

According to evidence-based guidelines, ${ }^{25,44}$ the first indication for epilepsy surgery in all age groups is resistance to antiepileptic drugs (Table 5). An evidence-based consensus definition of drug-resistant epilepsy was recently published and is recommended in the selection of patients for surgical evaluation. ${ }^{10}$ Also, consideration for surgery requires that the seizures must be disabling, regardless of whether or not the seizures are associated with impaired awareness.

There are no RCTs of epilepsy surgery involving children. As such, indications in the pediatric group come from experts of the International League Against Epilepsy Subcommission for Pediatric Epilepsy Surgery, which are based on evidence from surgical case series (Table 5). ${ }^{46}$ They recommend surgical evaluation for children with complex epilepsy syndromes, those who require complex surgery, or those for whom a definite electroclinical syndrome has not been confirmed but who have stereotyped or lateralized seizures or focal findings. All children with an MRI lesion amenable to surgical removal and all children less than three years old should undergo surgical evaluation, regardless of the response to medical treatment, because such children are more likely to experience a relapse or epileptic encephalopathy. ${ }^{46}$

There are no evidence-based contraindications to epilepsy surgery, although the existence of a severe active psychiatric condition (e.g., active psychosis) or medical comorbidities precluding surgery are generally accepted as contraindications. However, surgery should be considered in such individuals with drug-resistant epilepsy if these conditions resolve. Failure to identify an epileptic focus after a complete surgical evaluation by an epilepsy specialist is usually a contraindication to surgery, except for patients with drop attacks. Here, corpus callosotomy may be beneficial in reducing the frequency of drop attacks.

Timely consideration of epilepsy surgery is important, although the exact time when a patient should be referred is still uncertain. Although there are no RCTs comparing outcomes among patients who undergo surgery early in the course of their illness compared with those who undergo late surgery, a recent RCT has shown that surgery within two years of the 


\section{Box 2: Resources for physicians and patients}

- Revised terminology and concepts for organization of seizures and epilepsies: Report of the International League Against Epilepsy's Commission on Classification and Terminology, 2005-2009. www.ilae.org/Visitors/Centre/ctf/ctfoverview.cfm

- American Academy of Neurology Practice Parameter and Guidelines (e.g., temporal lobe and localized neocortical resections for epilepsy): www.aan.com/go/practice/guidelines

- Free online clinical decision tool from the Canadian Appropriateness Study of Epilepsy Surgery to assist physicians in identifying which patients should be referred for an epilepsy surgery evaluation. www.epilepsycases.com

- Canadian League Against Epilepsy: www.clae.org/

- Canadian Epilepsy Alliance (information for patients about epilepsy surgery): www.epilepsymatters.com/english/tresurgery.html

development of drug-resistant epilepsy is superior to medical therapy. ${ }^{15}$ Longitudinal studies confirm that an earlier age at surgery and a shorter duration of epilepsy are associated with better neuropsychiatric and psychosocial outcomes. ${ }^{47}$ Timely intervention is especially important in children to avoid the development of persistent psychosocial and cognitive difficulties later in life. ${ }^{46}$ In general, patients for whom two or more antiepileptic drugs fail are unlikely to ever achieve sustained seizure freedom with additional drug trials., ${ }^{5,10,11}$ Thus, waiting for spontaneous remission is not justified.

Figure 1 outlines our suggested approach to the care of patients with newly diagnosed epilepsy, including when to refer to an epilepsy program. Clinical decision tools are also emerging to guide clinicians in identifying patients who may benefit from an epilepsy surgery evaluation (Box 2). ${ }^{32,48}$

\section{Unanswered questions}

Despite evidence from RCTs and clinical practice guidelines recommending epilepsy surgery, patients are not referred for surgery evaluation at the expected rates. ${ }^{49}$ Greater understanding is needed regarding barriers to epilepsy surgery, and knowledge-transfer efforts are needed to inform clinicians and patients about the relative effectiveness of antiepileptic drugs and epilepsy surgery.

Ways to improve the present surgical success rate of $60 \%-70 \%$ are needed. Larger resections seem more effective, but smaller resections may be associated with less morbidity. Potential advantages and disadvantages of minimally invasive surgical procedures need to be evaluated. New techniques are needed to better characterize the areas of the brain where seizures originate. Although great strides have been made in the surgical evaluation and care of patients with epilepsy, ongoing research is warranted to answer these questions and further improve outcomes for patients with epilepsy.

\section{References}

1. Prilipko L, Saxena S. Atlas: Country resources for neurological disorders 2004. Geneva (Switzerland): World Health Organization; 2004.

2. Begley CE, Famulari M, Annegers JF, et al. The cost of epilepsy in the United States: an estimate from population-based clinical and survey data. Epilepsia 2000;41:342-51.

3. Feindel W, Leblanc R, de Almeida AN. Epilepsy surgery: historical highlights 1909-2009. Epilepsia 2009;50(Suppl 3):131-51.

4. Ontario Health Technology Advisory Committee. OHTAC recommendation: care for drug-refractory epilepsy in Ontario. Toronto: Health Quality Ontario; 2012.

5. Kwan P, Brodie MJ. Early identification of refractory epilepsy. $N$ Engl J Med 2000;342:314-9.

6. Schiller Y, Najjar Y. Quantifying the response to antiepileptic drugs: effect of past treatment history. Neurology 2008;70:54-65.

7. Berg AT, Levy SR, Testa FM, et al. Remission of epilepsy after two drug failures in children: a prospective study. Ann Neurol 2009; 65:510-9.

8. Sillanpää M, Schmidt D. Natural history of treated childhoodonset epilepsy: prospective, long-term population-based study. Brain 2006;129(Pt 3):617-624.

9. Semah F, Picot MC, Adam C, et al. Is the underlying cause of epilepsy a major prognostic factor for recurrence? Neurology 1998;51:1256-62.

10. Kwan P, Arzimanoglou A, Berg AT, et al. Definition of drug resistant epilepsy: consensus proposal by the ad hoc Task Force of the ILAE Commission on Therapeutic Strategies. Epilepsia 2010;51:1069-77.

11. Brodie MJ, Barry SJ, Bamagous GA, et al. Patterns of treatment response in newly diagnosed epilepsy. Neurology 2012;78:1548-54.

12. Callaghan BC, Anand K, Hesdorffer D, et al. Likelihood of seizure remission in an adult population with refractory epilepsy. Ann Neurol 2007;62:382-9.

13. Kerr MP. The impact of epilepsy on patients' lives. Acta Neurol Scand Suppl 2012;194:1-9.

14. Wiebe S, Blume WT, Girvin JP, et al. A randomized, controlled trial of surgery for temporal-lobe epilepsy. N Engl J Med 2001; 345:311-8.

15. Engel J Jr, McDermott MP, Wiebe S, et al. Early surgical therapy for drug-resistant temporal lobe epilepsy: a randomized trial. JAMA 2012;307:922-30.

16. Malikova H, Liscak R, Vojtech Z, et al. Stereotactic radiofrequency amygdalohippocampectomy: Does reduction of entorhinal and perirhinal cortices influence good clinical seizure outcome? Epilepsia 2011;52:932-40.

17. Quigg M, Rolston J, Barbaro NM. Radiosurgery for epilepsy: clinical experience and potential antiepileptic mechanisms. Epilepsia 2012;53:7-15.

18. Tecoma ES, Iragui VJ. Vagus nerve stimulation use and effect in epilepsy: What have we learned? Epilepsy Behav 2006;8:127-36.

19. Tellez-Zenteno JF, Wiebe S. Hippocampal stimulation in the treatment of epilepsy. Neurosurg Clin N Am 2011;22:465-75.

20. Morrell MJ. Responsive cortical stimulation for the treatment of medically intractable partial epilepsy. Neurology 2011;77:1295-304.

21. Fisher R, Salanova V, Witt T, et al. Electrical stimulation of the anterior nucleus of thalamus for treatment of refractory epilepsy. Epilepsia 2010;51:899-908.

22. Velez-Ruiz NJ, Klein JP. Neuroimaging in the evaluation of epilepsy. Semin Neurol 2012;32:361-73.

23. Burch J, Marson A, Beyer F, et al. Dilemmas in the interpretation of diagnostic accuracy studies on presurgical workup for epilepsy surgery. Epilepsia 2012;53:1294-302. 
24. Wiebe S, Matijevic S, Eliasziw M, et al. Clinically important change in quality of life in epilepsy. J Neurol Neurosurg Psychiatry 2002;73:116-20.

25. Engel J Jr, Wiebe S, French J, et al. Practice parameter: temporal lobe and localized neocortical resections for epilepsy: report of the Quality Standards Subcommittee of the American Academy of Neurology, in association with the American Epilepsy Society and the American Association of Neurological Surgeons. Neurology 2003;60:538-47.

26. Spencer SS, Berg AT, Vickrey BG, et al. Initial outcomes in the Multicenter Study of Epilepsy Surgery. Neurology 2003;61:1680-5.

27. Schmidt D, Stavem K. Long-term seizure outcome of surgery versus no surgery for drug-resistant partial epilepsy: a review of controlled studies. Epilepsia 2009;50:1301-9.

28. Murphy M, Smith PD, Wood M, et al. Surgery for temporal lobe epilepsy associated with mesial temporal sclerosis in the older patient: a long-term follow-up. Epilepsia 2010;51:1024-9.

29. Dunkley C, Kung J, Scott RC, et al. Epilepsy surgery in children under 3 years. Epilepsy Res 2011;93:96-106.

30. Téllez-Zenteno JF, Dhar R, Wiebe S. Long-term seizure outcomes following epilepsy surgery: A systematic review and meta-analysis. Brain 2005;128:1188-98.

31. Sperling MR, Feldman H, Kinman J, et al. Seizure control and mortality in epilepsy. Ann Neurol 1999;46:45-50.

32. Choi H, Sell RL, Lenert L, et al. Epilepsy surgery for pharmacoresistant temporal lobe epilepsy: a decision analysis. JAMA 2008;300:2497-505

33. Wiebe S, Jette N. Epilepsy surgery utilization: Who, when, where, and why? Curr Opin Neurol 2012;25:187-93.

34. Hamiwka LD, Macrodimitris S, Tellez-Zenteno J, et al. Social outcomes after temporal or extra-temporal epilepsy surgery: a systematic review. Epilepsia 2011;52:870-9.

35. Wiebe S, Gafni A, Blume WT, et al. An economic evaluation of surgery for temporal lobe epilepsy. J Epilepsy 1995;8:227-35.

36. Picot MC, Neveu D, Kahane P, et al. Cost-effectiveness of epilepsy surgery in a cohort of patients with medically intractable partial epilepsy-preliminary results [article in French]. Rev Neurol (Paris) 2004;160 Spec No 1:5S354-367.

37. Bowen JM, Snead OC, Chandra K, et al. Epilepsy care in Ontario: an economic analysis of increasing access to epilepsy surgery. Ont Health Technol Assess Ser 2012;12:1-41.

38. Téllez-Zenteno JF, Hernández Ronquillo L, Moien-Afshari F, et al. Surgical outcomes in lesional and non-lesional epilepsy: a systematic review and meta-analysis. Epilepsy Res 2010;89:310-8.

39. Téllez-Zenteno JF, Dhar R, Hernández-Ronquillo L, et al Long-term outcomes in epilepsy surgery: antiepileptic drugs, mortality, cognitive and psychosocial aspects. Brain 2007;130: 334-345

40. Spencer SS, Berg AT, Vickrey BG, et al. Health-related quality of life over time since resective epilepsy surgery. Ann Neurol 2007; 62:327-34
41. Hader WJ, Tellez-Zenteno J, Metcalfe A, et al. Complications of epilepsy surgery - a systematic review of focal surgical resections and invasive EEG monitoring. Epilepsia 2013;54:840-7

42. Sherman EM, Wiebe S, Fay-McClymont TB, et al. Neuropsychological outcomes after epilepsy surgery: systematic review and pooled estimates. Epilepsia 2011;52:857-69.

43. Langfitt JT, Westerveld M, Hamberger MJ, et al. Worsening of quality of life after epilepsy surgery: effect of seizures and memory decline. Neurology 2007;68:1988-94.

44. Labiner DM, Bagic AI, Herman ST, et al. Essential services, personnel, and facilities in specialized epilepsy centers - revised 2010 guidelines. Epilepsia 2010;51:2322-33.

45. Berg AT, Berkovic SF, Brodie MJ, et al. Revised terminology and concepts for organization of seizures and epilepsies: report of the ILAE Commission on Classification and Terminology, 2005-2009. Epilepsia 2010;51:676-85.

46. Cross JH, Jayakar P, Nordli D, et al. Proposed criteria for referral and evaluation of children for epilepsy surgery: recommendations of the Subcommission for Pediatric Epilepsy Surgery. Epilepsia 2006;47:952-9

47. Helmstaedter C, Kurthen M, Lux S, et al. Chronic epilepsy and cognition: a longitudinal study in temporal lobe epilepsy. Ann Neurol 2003:54:425-32.

48. Jette N, Quan H, Tellez-Zenteno JF, et al. Development of an online tool to determine appropriateness for an epilepsy surgery evaluation. Neurology 2012;79:1084-93.

49. Haneef Z, Stern J, Dewar S, et al. Referral pattern for epilepsy surgery after evidence-based recommendations: a retrospective study. Neurology 2010;75:699-704.

Affiliations: Department of Clinical Neurosciences (Jette, Wiebe), Hotchkiss Brain Institute (Jette, Wiebe), University of Calgary, Calgary, Alta.; Department of Community Health Science (Jette, Wiebe), Institute for Public Health (Jette, Wiebe), University of Calgary, Calgary, Alta.; Department of Neurology (Reid), David Geffen School of Medicine (Reid), University of California Los Angeles, Los Angeles, Calif.

Contributors: All of the authors contributed substantially to the conception, writing and revisions of the manuscript. All of the authors approved the final version submitted for publication.

Funding: Nathalie Jette is the recipient of an Alberta Innovates Health Solutions (AIHS) Award (Population Health Investigator) and a Canada Research Chair Tier 2 in Neurological Health Services Research. Aylin Reid is the holder of a Clinician Fellowship Award from AIHS. Samuel Wiebe holds the Hopewell Professorship for Clinical Neurosciences Research at the Hotchkiss Brain Institute, University of Calgary. 